\title{
PRACTICAR Y ENSEÑAR LA FILOSOFÍA EN SU PROFUNDIDAD METAFÍSICA
}

Mauro Mantovani*

\section{Introducción}

En esta contribución queremos subrayar la necesidad de la filosofía para progresar en el conocimiento de la verdad, y para hacer siempre más humana la existencia del hombre. También el nuevo "Decreto de reforma de los estudios eclesiásticos de Filosofía”, recién publicado, reafirma -citando muchas veces la Encíclica Fides et ratio- la importancia de la filosofía.

La filosofía 'contribuye directamente a formular la pregunta sobre el sentido de la vida y a trazar la respuesta'. Esta pregunta nace, tanto de la maravilla que el hombre experimenta ante las personas y el cosmos como de las experiencias dolorosas y trágicas que acometen su vida. El saber filosófico se configura, entonces, como 'una de

* Mauro Mantovani, salesiano, italiano. Decano de la Facultad de Filosofía de la Universidad Pontificia Salesiana de Roma, donde desarrolla actividades de enseñanza e investigación en ámbitos de filosofía teorética, metodología de investigación filosófica y relación entre ciencia, filosofía y teología. 
las tareas más nobles de la humanidad' (cfr. Juan Pablo II, Fides et Ratio, 1998, n.3) ${ }^{1}$.

Platón, en la Apología de Sócrates, habla así de la tarea del filósofo.

Ni otra cosa hago yo en realidad con este dar vueltas mío, más que persuadiros a vosotros, jóvenes y viejos, de que no debéis tener cuidado del cuerpo ni de las riquezas ni de ninguna otra cosa antes ni más que del alma, de forma que ésta se haga perfecta y virtuosa [...]. Os digo que precisamente esto es para el hombre el bien mayor, razonar cada día sobre la virtud y sobre los otros argumentos sobre los cuales me habéis oído hablar, e investigar sobre uno mismo y sobre los demás, y que una vida que no haga estas investigaciones, no es digna de ser vivida (cfr. Platón Apología de Sócrates, XVII e XVIII).

La pregunta de filosofía que hoy parece emerger de nuevo cada vez con mayor insistencia de la sociedad no debe leerse de forma apresurada ni ingenua, sino que merece una reflexión atenta, porque se encuentra la pregunta de sentido por parte de quien, no queriendo confiarse a alguna de tantas 'psicoterapias' que propone el mercado, reconoce en la filosofía un instrumento de clarificación de la propia visión del mundo y piensa que una mayor conciencia cognitiva pueda aliviar las dificultades de la existencia; o más sencillamente, ayudar a vivir mejor los momentos de crisis y de cambio. ¿Y dónde encontrar una respuesta a tales problemas, si no en esta forma de saber que -en su historia, en sus textos y en sus rigurosas argumentaciones- encierra el más grandioso patrimonio de razonamiento y de sentido que se pueda imaginar? (cfr. Bernardi-Massaro, 2005: 7).

¿Por qué el interés por la filosofía? Ante todo porque la cuestión del sentido es un 'nudo' existencial fundamental, empezando por el sentido de las experiencias cotidianas de la vida. 
La pregunta sobre el sentido reclama el porqué concreto de la existencia y la interpretación personal de las diversas experiencias que la componen y la fragmentan. Central, en este nivel, es la percepción subjetiva que permite respirar el sentido del recorrido personal existencial y de las aventuras programadas o sufridas. Sin embargo, no todo puede ser limitado al plano subjetivo, porque el sentido de las cosas va mucho más allá que la percepción personal del sentido. El proceso se desarrolla, de hecho, a un nivel más profundo y comprometedor, hasta llegar a alcanzar la relevancia existencial de cada persona: se va desde la visión subjetiva del sentido a la 'objetiva', que reviste la vida humana como tal, la realidad más allá de nuestra comprensión. La llamada al sentido traslada así, más allá de la sensibilidad personal y afectiva, a la dimensión de una racionalidad pensada y pensativa (cfr. Tonelli, 2010: 149).

En estas páginas pretendemos ofrecer una breve reflexión, si bien no exhaustiva, sobre el valor de la práctica y de la enseñanza de la filosofía, y dentro de ella, de la dimensión netamente metafísica, sin contraponerla a las otras disciplinas filosóficas, permite de forma insustituible unir la pregunta sobre el 'sentido' con la pregunta por la verdad, y ofrecer una concepción equilibrada de la relacionalidad -por tanto ni absolutizada, ni mucho menos relativista-, que aunque sea intrínsecamente pluridimensional, no por ello llega a ser equívoca. En este sentido una correcta metodología filosófica, una apasionada, pero siempre coherente, aproximación a las fuentes, y la práctica de una 'racionalidad abierta', son los ingredientes que permiten gustar existencialmente la búsqueda filosófica y el valor de la interdisciplinariedad y de la transdisciplinaridad. 


\section{Las preguntas filosóficas: entre 'verdad' y 'sentido'}

La vida propone sus interrogantes, y en ellos -como sabemos- tiene su origen la filosofía. Así, existencialmente, si ha de existir filosofía y ésta quiere ser honesta, tendrá que dar cuenta de la 'vida de la razón' para que la razón lo sea de la vida. Primum vivere, deinde philosophari!

Por ello se pregunta justamente, a tal respecto, D. 62 Bermejo:

¿Cómo expresar la vida en su sobreabundancia, complejidad y dinamismo? ¿Cómo verter en palabras la experiencia humana; amalgama de contornos imprecisos, hecha de contrastes, paradojas, ambivalencias; de emociones, deseos, recuerdos; de fe, amor y esperanza; de temores, ilusiones, frustraciones y consuelos; de comedia y de tragedia; de corporalidad, tradición, historia, lengua; de luces y sombras y claroscuros...? (Bermejo, 2010: 15).

La lectura y la frecuencia de los clásicos de la filosofía -Platón y Aristóteles, Epicuro y los Estoicos, Agustín y Tomás, Montaigne, Descartes y Pascal, Kant y Hegel, Kierkegaard y Nietzsche, Husserl y Heidegger, etcétera, y, si quisiéramos ensanchar el campo, como es obligado, la Biblia, las Upanishad y el Corán -se configura como una auténtica 'cura del alma', una especie de biblioterapia que en algunos casos es más eficaz que las medicinas. Es en este escenario donde se sitúan las que han sido denominadas las 'prácticas filosóficas', como por ejemplo el diálogo socrático, el café filò, las varias ramas de la ética de los quehaceres, el counseling, la philosophy of management, la philosophy for children (o, mejor todavía, la philosophy with children), los festival della filosofía.

Estas iniciativas se han reafirmado en la segunda mitad del siglo XX, especialmente en el mundo anglosajón, 
en el cuadro del 'viraje ético', que ha tenido el mérito de relanzar la responsabilidad de la filosofía también al frente social, como cura intelectual de las personas, más que como incremento del conocimiento. Podemos decir, por tanto, que es gracias a su valor 'práctico' que la filosofía, lejos del ocaso, ha vuelto a la actualidad como lugar privilegiado de la reflexión sobre las razones del actuar (cfr. Bernardi-Massaro, 2005: 7-8).

Para quien además se adentra en la 'práctica filosófica' en el sentido más 'profesional' y se apasiona por la investigación filosófica surge muy pronto la necesidad de que, si por una parte resulta obligado tener en cuenta las contribuciones ya elaboradas, los criterios fundamentales de criticidad y cientificidad comúnmente practicados en el propio campo de investigación, por otra parte-sin ridícula presunción pero tampoco con falsa modestia-, vale la pena aplicar lo que decía Kant a propósito del Iluminismo: ten el valor de servirte de tu inteligencia! Para no seguir siendo 'menores' de por vida, es necesaria la capacidad de decisión y valor, vencer el miedo de osar y la pereza contraria a cualquier forma de fatiga. Dirigirse al médico por la salud, al director espiritual para la conciencia, a un buen libro para la instrucción, no son decisiones equivocadas, pero no deben transformarse -decía Kant- en apoyos permanentes para ayudar a los niños a estar de pie. Llega un momento en que es necesario caminar con las propias piernas, aunque al principio se esté muy inestable e inseguro. El filósofo alemán previene que no es fácil usar la propia inteligencia, es más, aparece la tentación de pasar de las viejas ataduras y prejuicios a otros nuevos para sentirse seguro.

Kant hace una bella distinción entre el uso público y privado de la razón: cada ciudadano, en calidad de buscador de la verdad, debe ser plenamente libre de expresar sus propias reflexiones. En calidad de funcionario tiene el deber de obedecer. Por ejemplo, un oficial del ejército 
debe obedecer las órdenes de sus superiores, pero como estudioso, puede someter al público sus observaciones sobre los errores del servicio militar (cfr. Kant, 1784 en Berlinische: 485-486). Un investigador primero demuestra saber aplicar los criterios compartidos de cientificidad, luego puede proponer observaciones para mejorarlos. En cualquier caso, si los adopta sin discutirlos, queda siempre la responsabilidad del uso de su inteligencia para extraer lo mejor de los elementos recogidos.

En este sentido, el crecimiento en atención a la pluralidad de perspectivas para captar la realidad como un conjunto articulado, no debe ser confundido con la pretensión de exhaustividad, ni tampoco la cientificidad debe confundirse con la verdad fundamental, de otro modo, se caería en la pretensión holística de control total, postura ya criticada por Popper (1981: 79). Cada análisis, cada descripción selecciona algunos aspectos de una realidad, nunca todos en modo completo, precisamente porque todos son inagotables, por lo que cualquier conocimiento es siempre limitado. El tener en cuenta el hecho de que se operan continuamente unas selecciones, y la confrontación con otras perspectivas, ayuda a no perder de vista el orden del conjunto sin la pretensión de poder dominarlo a placer, sino siempre con cautela y atención a las implicaciones. Así se forma en un sano realismo. El conocimiento es, en efecto, apertura de la mente a la realidad bajo el impulso de exigencias imperiosas, pero la urgencia de soluciones útiles puede empujar a distorsionarla hasta crear soluciones aparentes con resultados demoledores. Los datos obtenidos deben ser valorados atentamente sin perder de vista el conjunto, sin forzarlos como si de debiese probar 'la cuadratura del círculo’. Esto lo enseña la práctica filosófica, siendo fundamental experimentarla si se quiere introducir luego a los otros en su ejercicio y enseñarla. 
Justamente a partir de estos elementos, la filosofía muestra una dimensión suya sapiencial, relacionada con su propia definición nominal. Es, de hecho, dirigida hacia la respuesta -de forma ordenada y sistemática- a los intereses e interrogantes existenciales más importantes y fundamentales, o sea, la búsqueda de lo verdadero y del bien, y por tanto su "alcance auténticamente metafísico, capaz de trascender los datos empíricos para llegar, en su búsqueda de la verdad, a algo absoluto, último y fundamental" (Juan Pablo II, Fides et Ratio, 1998 n. 83) si bien conocido progresivamente a lo largo de la Historia.

Esta cuestión es particularmente significativa $y$, al mismo tiempo, necesaria en el contexto cultural actual.

La sabiduría considera los principios primeros y fundamentales de la realidad, y busca el sentido último y pleno de la existencia, permitiéndose, de esta forma, ser 'la instancia crítica decisiva que señala a las diversas ramas del saber científico su fundamento y su límite', y situarse 'como última instancia de unificación del saber y del obrar humano, impulsándolos a avanzar hacia un objetivo y un sentido definitivos'.

Por esto practicar la filosofía, y la metodología que la caracteriza en su ser más auténtico, significa conducir "una actividad intelectual que precisa que se suspendan las opiniones inmediatas, que se permanezca lejos de las discusiones espontáneas, en la medida en que éstas nos vuelven a llevar a nuestros prejuicios y a nuestras convicciones superficiales" (cfr. Folscheid y Wunenberger, 1996: 18), obligando a considerar y a 'leer dentro' cada situación, desde las cuestiones existenciales más densas hasta los más pequeños hechos que llenan la normal vida cotidiana, con la necesaria atención y profundidad.

Ocuparse de la filosofía, ayuda de este modo, desde el punto de vista epistemológico, a superar el aspecto 
sectorial del saber que "en la medida en que comporta una aproximación parcial a la verdad, con la consiguiente fragmentación del sentido, impide la unidad interior del hombre contemporáneo" (Juan Pablo II, Fides et Ratio 1998, n. 85). La reflexión sobre la verdad en sí misma es desde siempre un argumento central de la filosofía: ya en Aristóteles se lee que "es correcto llamar a la filosofía ciencia de la verdad. Fin de la ciencia teorética y la verdad, fin de la ciencia práctica y la acción” (cfr, Aristóteles 993 b29-31).

Entre las transformaciones de la cultura dominante, algunas, particularmente profundas, afectan a la concepción de la verdad. En efecto, muy a menudo, se advierte una desconfianza relacionada con la capacidad de la inteligencia humana de alcanzar una verdad objetiva y universal, con la cual las personas puedan orientarse en su vida. Además, el impacto de las ciencias humanas y las consecuencias del desarrollo científico y tecnológico provocan nuevos desafíos ${ }^{3}$.

Por eso nos parece que la pregunta sobre la verdad llegue a comprender también la del sentido, precisamente porque el interrogante sobre los significados de la vida se abre naturalmente a la cuestión de la verdad integral de la existencia, y se convierte por ello en 'filosofía primera', metafísica.

¿Pienso porque soy hombre, o soy hombre porque pienso? En este quiasmo se condensa de dos modos diferentes de pensar el hombre y su realidad: la moderna -soy hombre porque pienso- y la contramoderna -pienso porque soy hombre: pensar el pensamiento (Razón Pura) o pensar al ser que piensa (razón impura). Expresado de otro modo, el debate entre la razón inhumana y la razón humana, entre la razón ilimitada y la razón limitada o entre el hombre incondicionado y la condición humana (Bermejo, 2010: 9). 
Hay hoy un peligro de doble exceso, por una parte el rechazo de las racionalidades y por otro, el de conservar posiciones racionalísticas y neopositivistas que, además, exaltan un único modelo de racionalidad, y no admitiendo otra cosa que la razón. En este sentido es interesante resaltar cómo ha sido precisamente en el ambiente filosófico de lengua española -aun no siendo, por supuesto, el único-, donde en el siglo XX se ha desarrollado una reflexión antropológica dirigida a subrayar otras dimensiones, aparte de la puramente racional, que pertenecen a la existencia humana.

Excluir la razón y no admitir más que la razón. ¡El hombre es caña débil, la más débil de las criaturas; pero pensante. La grandeza de la razón consiste en reconocer su debilidad. Pensamiento es más que razón. Es sentimiento, es deseo, es fe, es vida [...]. El hombre no es solo, ni sobre todo, animal racional; sino, además, animal paradójico, contradictorio, insatisfecho, pasional, afectivo, monstruoso y angélico. A esta corriente -mejor contracorriente- de pensamiento cabe adscribir grosso modo el llamado pensamiento español. Unamuno, Santayana, Ortega, Zubiri, Aranguren y Zambrano -no solo ellos, pero sobre todo ellos en el siglo XX- representan de modo inequívoco, aunque con matices diferentes, un tono, un estilo y un contenido reflexivos decididamente anticartesianos (ibíd.: 11-12).

Según D. Bermejo la contribución más lúcida del pensamiento español a la filosofía en general es: "filosofía de la vida concreta en su pertinaz resistencia a la simplificación y contra la 'dictatura de la razón' pura, geométrica, fría y endiosada (ibíd.: 16). Así, a tal respecto, M. de Unamuno:

Homo sum: nihil humanum a me alienum puto, dijo el cómico latino. Y yo diría más bien, nullum hominem a me 
alienum puto; soy hombre, a ningún otro hombre estimo extraño. Porque el adjetivo humanus me es tan sospechoso como su sustantivo abstracto humanitas, la humanidad. Ni lo humano ni la humanidad, ni el adjetivo simple, ni el sustantivado, sino el sustantivo concreto: el hombre. El hombre de carne y hueso, el que nace, sufre y muere -sobre todo muere-, el que se ve y a quien se oye, el hermano, el verdadero hermano [...]. Y este hombre concreto, de carne y hueso, es el sujeto y el supremo objeto a la vez de toda filosofía, quiéranlo o no ciertos sedicentes filósofos (Unamuno, 1971: 9-10).

\section{La utilidad de la metafísica}

El 'elemento metafísico es el camino obligado para superar la situación de crisis que afecta hoy a grandes sectores de la filosofía y para corregir así algunos comportamientos erróneos difundidos en nuestra sociedad'. En esta prospectiva, los filósofos están invitados a recuperar con fuerza la 'vocación originaria' de la filosofía: la búsqueda de lo verdadero y su dimensión sapiencial y metafísica ${ }^{4}$.

Así se lee en el nuevo Decreto de reforma de la Sagrada Congregación para la Educación Católica. El pensar y el decir condicen, en efecto, inexorablemente, a las cuestiones del ser. La sapiencialidad metafísica empuja a la 'excavación' filosófica hasta la individualización de los principios primeros del ser, de sus causas fundamentales.

La sabiduría considera los principios primeros y fundamentales de la realidad, y busca el sentido último y pleno de la existencia, permitiéndose, de esta forma, ser 'la instancia crítica decisiva que señala a las diversas ramas del saber científico su fundamento y su límite', y situarse 'como última instancia de unificación del saber y del 
obrar humano, impulsándolos a avanzar hacia un objetivo y un sentido definitivos'. El carácter sapiencial de la filosofía implica su 'alcance auténticamente metafísico, capaz de trascender los datos empíricos para llegar, en su búsqueda de la verdad, a algo absoluto, último y fundamental', si bien conocido progresivamente a lo largo de la historia. De hecho, la metafísica o filosofía primera trata del ente y de sus atributos y, de esta forma, se eleva al conocimiento de las realidades espirituales, buscando la Causa primera de todo. Sin embargo, este subrayado del carácter sapiencial y metafísico no se debe entender como una concentración exclusiva sobre la filosofía del ser, ya que todas las diversas partes de la filosofía son necesarias para el conocimiento de la realidad. Es más, el propio campo de estudio y el método específico de cada una se deben respetar en nombre de la adecuación a la realidad y de la variedad de los modos humanos de conocer ${ }^{5}$.

Es justamente la práctica de la metafísica lo que muestra que el hombre es capaz de llegar a una visión unitaria y orgánica del saber, a un horizonte de una razón abierta.

La filosofía que se cultiva al interno de la Universidad está llamada en primer lugar a acoger el reto de ejercitar, desarrollar y defender una racionalidad de 'horizontes más amplios', mostrando que 'es de nuevo posible ensanchar los espacios de nuestra racionalidad [...], conjugar entre sí la teología, la filosofía y las ciencias, respetando plenamente [...] su recíproca autonomía, pero siendo también conscientes de su unidad intrínseca. En el plano institucional, volver a encontrar 'este gran logos', 'esta gran amplitud de la razón' es propiamente la gran tarea de la Universidad $^{6}$.

En este sentido, verdad y amor en la perspectiva cristiana no pueden estar separados. 
Por una parte, la defensa y la promoción de la verdad son una forma esencial de caridad: 'Defender la verdad, proponerla con humildad y convicción y testimoniarla en la vida son formas exigentes e insustituibles de caridad'. Por otra parte, solo la verdad permite una caridad verdadera. 'La verdad es luz que da sentido y valor a la caridad'. Finalmente, la verdad y el bien están estrechamente conectados: 'La verdad significa algo más que el saber: el conocimiento de la verdad tiene como finalidad el conocimiento del bien. Este es también el sentido del interrogante socrático: ¿Cuál es el bien que nos hace verdaderos? La verdad nos hace buenos y la bondad es verdadera'. Mediante la propuesta de una visión orgánica del saber que no está separada del amor, la Iglesia puede aportar su específica contribución, capaz de incidir eficazmente también en los proyectos culturales y sociales ${ }^{7}$.

Reafirmar hoy la importancia de la metafísica significa sostener que el papel central de la metafísica debe, por tanto, ser entendido a la luz de la importancia de la filosofía en el conocimiento humano. Esa está ligada directamente con el deseo humano de conocer la verdad y de organizarla. La experiencia muestra en efecto que el conocimiento de la filosofía ayuda a organizar mejor, en cooperación con otras disciplinas, el estudio de cualquier ciencia. La metafísica quiere conocer el conjunto de la realidad -que culmina en el conocimiento de la Causa primera de todo- y mostrar la mutua relación entre los diversos campos del saber, evitando la cerrazón de cada ciencia en sí misma.

Con la adquisición de los 'habitus' intelectuales, científicos y sapienciales, la razón aprende a conocer más allá de los datos empíricos. En modo particular, el debate intelectual en una sociedad pluralista, fuertemente amenazada por el relativismo y por las ideologías, o bien en una sociedad donde falta una auténtica libertad, exige [...] la 
adquisición de una sólida forma mentis filosófica. Estos 'habitus' permiten pensar, conocer y razonar con precisión, y también dialogar con todos en modo incisivo y sin temores. La dimensión de los 'habitus' está, de todas formas, enlazada con la asimilación de los contenidos firmemente adquiridos, es decir, brota del conocimiento y de la profundización de las verdades más importantes ${ }^{8}$.

Hablando de las materias obligatorias fundamentales del primer ciclo de estudios universitarios, la nueva Reforma de los estudios eclesiásticos de Filosofía requiere "una introducción general que pretenderá, en modo particular, mostrar la dimensión sapiencial de la filosofía" y pone como primera de las disciplinas filosóficas principales: la "metafísica (entendida como filosofía del ser y teología natural)", añadiendo que "dada la importancia particular de la metafísica, a esta disciplina le deberá corresponder un adecuado número de los créditos"9.

Esta indicación no pretende en absoluto subordinar el valor de otras disciplinas filosóficas, u oponer ontología y antropología, ni mucho menos avalar una postura racionalista que poco a poco parezca alejarse -en nombre de la abstracción metafísica- hacia la realidad existencial, reduciéndola casi a ser lo que lúcidamente M. Zambrano así denunciaba.

Y es que a partir del pensamiento cartesiano la conciencia ganó en claridad y nitidez y, al ensancharse, se apoderó del hombre todo. Y lo que iba quedándose fuera no eran cosas, sino nada menos que la realidad, la realidad oscura y múltiple. Al reducirse el conocimiento a la razón solamente, se redujo también eso tan sagrado que es el contacto inicial del hombre con la realidad a un modo único: el de la conciencia. Quedaba la conciencia en su claridad lunar aislada hasta del propio cuerpo, donde no se sabe por qué azarosa contingencia venía a estar insertada [...]. El hombre se tornaba en simple soporte del conocimiento 
racional, con todo lo que esto conlleva de extraordinario, pero la realidad en torno se iba estrechando a su compás; a medida que el 'sujeto' se ampliaba, diríase que absorbiendo las funciones que el alma desempeñaba antes, la realidad se empequeñecía [...]. Pero este agostamiento de la realidad no tenía lugar de un modo uniforme sino de un modo que ha modificado en esencia la inserción del hombre como criatura viva en el universo (Zambrano, 1992: 180-181).

En este sentido, recuperar el valor de una metafísica de la existencia, del actus essendi entendido en su significado integral, no aleja de la vida, especialmente la humana, sino que la muestra en el conjunto y complejidad de sus significados.

La razón que no parte de la vida y que no vuelve a la vida, que es ajena a la vida y a ella se opone, no tiene sentido humano. La razón desencarnada, desvitalizada, desapasionada no es razón humana, sino deshumanizada. Una razón sin rostro no es razón de nadie. La razón deberá incorporar sentimiento, carne, pasión, religiosidad, deseo, entraña, sentido para poder ser expresión fiel del hombre completo, complejo e, incluso, contradictorio. Y solo entonces, cuando sea 'razón trágica', 'razón dramática', 'razón vital', 'razón poética, 'razón moral', 'razón simbólica', 'razón efectiva' o 'razón sentiente', podrá ser nombrada sin sospecha y con sentido. Y el hombre no será ya, por tanto, -y sólo- animal racional, sino 'animal de realidades', 'animal simbólico', 'animal paradójico', 'hombre de carne y hueso', 'animal enfermo', 'ser demediado', 'ser incompleto,' 'ser menesteroso', 'ser religado', 'ser constitutivamente moral', 'novelista,' 'poeta', náufrago' [...] un ser poliédrico y pluridimensional que se deja decir de modos diferentes, complementarios o contradictorios, pero siempre insuficientes, balbucientes, metafóricos [...]. Porque la existencia humana en su radical realidad es, antes y más que nada y siempre, vida (Bermejo, 2010: 15). 
Practicar la filosofía primera corrige aquella curiosidad que no busca encontrarse con la realidad y conocer la verdad, sino simplemente 'mirar' o 'experimentar'. Es lo que Heidegger también observa.

Cuando la curiosidad queda en libertad no se preocupa de ver para comprender lo visto, es decir, para entrar en una relación de ser con la cosa vista, sino que busca el ver tan solo por ver. Si busca lo nuevo, es solo para saltar nuevamente desde eso nuevo a otra cosa nueva. En este ver, el cuidado no busca una captación [de las cosas], ni tampoco estar en la verdad mediante el saber, sino que en él procura posibilidades de abandonarse al mundo (Heidegger, 2005: 195).

La filosofía primera también ayuda enfrentar aquella actitud típica de una cierta modernidad de buscar la evidencia solo en el sujeto, en cómo sea su conocimiento, recordando las categorías fundamentales de las propiedades trascendentales, los principios primeros del ser (a partir de la causalidad y de la finalidad) y de la categoría verdadera de la trascendencia, que parece ser todavía un estorbo más que una ayuda para una filosofía que vaya al corazón de la realidad.

'Trascendencia' (sea lo que sea lo que esta expresión abarque) implica objetos situados por encima del hombre, y de esos objetos es de lo que trata la teoría clásica. La teoría moderna - observa H. Jonas - trata de objetos que están por debajo del hombre: incluso los astros, dado que son cosas vulgares, están por debajo del hombre. No se puede tomar de ellos indicación alguna con respecto a fines. La expresión 'por debajo del hombre', que sin duda contiene una valoración, parece contradecir la afirmada 'neutralidad axiológica' de la ciencia. Ahora bien, esta neutralidad axiológica implica la neutralidad tanto de los objetos como de la ciencia: del lado de los objetos, su indiferen- 
cia frente a todo valor que se les pueda 'dar'. Pero lo que carece por sí mismo de valor interno está por debajo de aquello que es lo único por relación a lo cual puede recibir valor, y esta instancia es el hombre y la vida humana, que son la única fuente y polo de referencia de valor que nos queda [...]. La relación con una trascendencia objetiva queda hoy fuera de la teoría, de conformidad con sus reglas de evidencia, mientras que antes era la vida misma de la teoría (Jonas, 2000: 273).

A la filosofía, justamente por esta su identidad, corresponde también la irrenunciable tarea del servicio epistemológico que muestra toda su importancia en temáticas verdaderamente fundamentales y actuales, como por ejemplo la relación entre fe y ciencia; entre teología y disiciplinas científicas, entre antropología, ética y neuropsicosociobiología, etcétera.

$\mathrm{Su}$ aportación a la interdisciplinariedad resulta ser, a nuestro juicio, indicio de carácter imprescindiblemente fundativo, como por otra parte lo entendía Jacques Maritain cuando atribuía a la investigación filosófica, respecto a las disciplinas científicas, el papel de 'juez en última instancia', 'reguladora del saber científico' y 'árbitro epistemológico' (cfr. Maritain, 1981), no en términos de intromisión, sino en términos de un soporte (cfr. Mantovani-Amerise; 2008: 29-79; Bay y Toso 2009) que no obstante no tiene miedo de ser también una obligada relativización frente a los siempre presentes riesgos de absolutización del propio punto de vista y del propio método.

La sabiduría, en el sentido más elevado y riguroso, es en efecto bien expresada por Maritain en su amplio escrito, varias veces reeditado, Distinguir para unir. Los grados del saber, donde se afirma que la sabiduría es "un saber supremo, de objeto universal, que juzga las cosas según los primeros principios" (cfr. Maritain, 1981: 293). "El tema de la correcta integración de los saberes” (cfr. Falabe- 
lla en Mantovani, 2010: 287-308) es en efecto una cuestión eminentemente filosófica. En su interesante análisis de los varios tipos de saber, Maritain, como Aristóteles, coloca en el vértice la sabiduría y la distingue en sabiduría metafísica, sabiduría teológica y sabiduría mística: "Por encima de la sabiduría metafísica está la sabiduría teológica. Por encima de esta, finalmente, está la sabiduría infusa, llamada también teológica mística, que consiste en conocer el objeto esencialmente sobrenatural de la fe y de la teología" (cfr. Maritain, 1981: 300, cap. V).

\section{La didáctica de la filosofía}

La práctica de la filosofía primera, junta con la virtud de la studiositas (cfr. Tomás de Aquino II-II: q. 106) revela ante todo que el deseo de conocimiento, que es natural para el hombre, necesita ser ordenado.

Para poder llevar una vita buena, verdadera, es necesario conocer quiénes somos, profundizar en el conocimiento del ser humano. Eso, en buena medida, es la tarea de la educación. Paralelamente, destaca la necesidad de que el hombre posea una actitud filosófica ante la vida, que se pare a pensar y ame el silencio, en el que crece el conocimiento profundo. El conocimiento superficial de las cosas es en ocasiones el único conocimiento facilitado por la sociedad actual. Pero de esa forma es muy complicado ser verdaderamente libre. Todo esto, sin embargo, se verá facilitado con una correcta educación. Ésta significará poder darse la posibilidad de orientar el conocimiento hacia lo que de verdad le interesa como persona. Además, una base sólida de conocimientos ayudarán a adquirir mejor y más fácilmente nuevos conocimientos (Vásquez Ramos, 2011: 195). 
La admiración ante la realidad y el deseo de conocer están al comienzo de la filosofía. Es notorio que Aristóteles consideraba la theoria como una forma de vida, determinada por la virtud de lo mejor: "la única actividad -afirma X. Zubiri- que es plenamente amada por sí misma, y no por lo que pueda suministrar" (Zubiri, 1970: 53).

La enseñanza de la filosofía debe por ello recorrer una vía vital y existencial, en la que la búsqueda de la verdad asume también una dimensión ética.

Lo definitivo será la orientación que el hombre dé a su deseo de conocimiento. Si su ser se expresa en gran medida con su capacidad de conocer y de amar, ese amor a la verdad debe materializarse de alguna manera en la vida del hombre. Es más: todo lo que el hombre puede llegar a ser dependerá de cómo desarrolle su capacidad de amar y conocer. Así, su deseo de conocimiento será virtuoso o vicioso, según se oriente a su felicidad plena o no (Vásquez Ramos, 2011: 111).

"Me parece que descubrir qué somos es, fundamentalmente -aunque solo quizá entre otras cuestiones-, descubrir qué debemos ser. Y, por ello, en la medida en que no podemos evitar desear o lo que no podemos lograr desear": así afirmaba H.G. Frankfurt (2006:10). Y le hace eco D. Vázquez Ramos.

Aquella persona que conozca mejor quién es ella, cómo es y cuál es su verdadero fin, estará en mejores condiciones de realizar plenamente su vida, su ser persona. Pero tiene que ser un conocimiento no solo general, en el sentido de global, sino también, y sobre todo, un conocimiento actual, del ahora en el que vive inserto. Es el concepto griego de 'momento oportuno'. No olvidemos que lo único que realmente existe como real es lo presente, lo que existe hoy y ahora. Es lo que apunta Inciarte, al señalar que cada ahora deja su huella en el siguiente ahora; pero 
solo existe el ahora presente, lo que 'ocurre' en este instante (Vásquez Ramos, 2011: 115; cfr. Inciarte, 2004: cap IV, 99-116).

Ocuparse de filosofía significa, por ello, transmitir una pasión que estimula a profundizar, no se conforma con la superficialidad, no esconde las problemáticas tras fáciles conciliaciones, así como decía Kierkegaard: "la paradoja es la pasión del pensamiento y el pensador sin paradoja es como el amante sin pasión: un mediocre modelo" (Kierkegaard, 2007: 51).

Y de aquí se muestran esos elementos de ensanchamiento de la racionalidad que la vida misma pone delante a quien busca la verdad y vive su existencia con pasión y con apertura a la totalidad de la experiencia vivida.

En la poesía y en la religiosidad escapa el pensamiento a la constricción de la filosofía, convertida exclusivamente en ciencia del conocimiento, y encuentra campo expandido para expresar sin complejos las dimensiones prerracionales y transracionales del animal paradójico y creativo que es el ser humano y que ningún sistema filosófico o científico puede contener adecuada y exhaustivamente (Bermejo, 2010: 16).

La filosofía tiene en efecto el papel de pasar al análisis de las condiciones que posibilitan un contacto enriquecedor entre estas dos formas del saber. En este sentido se muestra el rol mediador de la filosofía en las relaciones entre ciencia y teología: ese es un 'espacio' de la racionalidad humana que se caracteriza por ser "ejercicio del amor a la sabiduría" y que justamente por eso puede mostrar, en la actual fragmentación del saber, su capacidad de ser elemento de cohesión que puede estimular una búsqueda de unidad del saber mismo. La discusión sobre la cuestión de la identificación de un rol 'fuerte' o de un rol 'débil' de 
servicio de esta mediación filosófica depende del modelo epistemológico adoptado.

Hay ahora una creciente demanda de cursos de filosofía en las universidades libres, y muchos adultos y ancianos se acercan a la filosofía. La principal motivación parece ante todo el deseo de comprender la actualidad con instrumentos conceptuales más profundos. En estos cursos se propone el método histórico-problemático que permite acercarse a autores y temáticas a través de su lugar en la historia, pero estimulando a los participantes a un confronto constructivo sobre las cuestiones planteadas. Objetivo de tal método es hacer nacer o consolidar una actitud verdaderamente libre y filosófica frente a los interrogantes siempre actuales sobre el hombre y sobre la vida, a partir de la capacidad de escucha y la formulación de ideas. Los instrumentos pueden ser varios: diapositivas, esquemas, antología de textos, glosario, redacción de textos breves (cfr. Cristoforetti en Desbouts - Mantovani, 2010: 201-211).

Así se lee en el Prefacio de un texto relativamente reciente de Metodología filosófica.

Estudiar filosofía quiere decir, ante todo, enfrentarse a un pasado: nadie comienza a filosofar solo, sin reconocerse en una tradición. La voluntad de recomenzar desde los inicios, desde el principio, que es característica de las filosofías más radicales, en vez de expresar el deseo de partir de cero, significa más bien la intención de retomar siempre de nuevo los problemas pensados en otro lugar, por otros. Así, el estudio de la filosofía pasa por la frecuentación directa y constante de los textos de los filósofos, que hay que aprender a leer, a interpretar, a comentar, y la historia de la filosofía no sirve solo para reconstruir de modo riguroso la turbación del pensamiento ajeno, sino también para reencontrar pensamientos todavía vivos y ricos de significado, que pueden dar a nuestra búsqueda 
el alimento que necesita (cfr. Zuanazzi en Folscheid-Wunenburger: 1996: 11-12).

En efecto, un primer principio fundamental, 'originario', que caracteriza la metodología de la investigación filosófica es la adecuada aproximación a las fuentes, gracias a la cual los diversos autores y las diversas filosofías pueden ser recolocadas en itinerarios, contextos, sistemas e interpretaciones coherentes, aunque nunca exhaustivas, "que las liberan de cualquier pesadez histórica y las elevan al rango de pensamientos vivos y actuales (Folscheid-Wunenburger: 1996: 19-20).

Es interesante considerar la discusión de las principales cuestiones abiertas en el campo de la enseñanza de la historia de la filosofía. La exposición de la historia de la filosofía en orden cronológico tiene la ventaja de presentar una reseña completa y la desventaja de la erudición que conlleva el escepticismo como reacción. La solución de privilegiar algunos autores reduce los peligros de superficialidad y de confusión, pero no elimina la erudición que causa indiferencia. La exposición por temas, ayuda a conectarse a los centros de interés de os estudiantes, pero corre el riesgo de perder el sentido del contexto histórico original y de transformarse en ideología. La exposición circular que se centra en un ambiente de referencia, lleva a una reconstrucción cultural que transforma los alumnos en investigadores críticos, conscientes de ser 'extranjeros' que son gradualmente conquistados por la vitalidad que el ambiente revela. M. Marin en su artículo Una proposta per l'insegnamento della storia della filosofia: la circolarità come mediazione tra diacronia e sincronia, la ricostruzione dell'ambiente culturale come fucina di mentalità critiche indica como temas didácticamente útiles estos ambientes filosóficos: para el periodo antiguo, la Academia platónica en el siglo IV a.C.; para el periodo medieval, París entre 
los años 1252 y 1259; para el periodo moderno Hegel en la universidad de Berlín; para el periodo contemporáneo Wittgenstein en Cambridge (Inglaterra) (cfr. Marin en Desbouts-Mantovani, 2010: 167-183).

La identidad de la metodología filosófica plantea, por lo demás, un problema particularmente interesante, mostrando que la metodología no es simplemente una serie de astucias técnicas o un conjunto de habilidades que desde fuera vienen a añadirse al saber.

En filosofía se puede adquirir un método de trabajo solamente si se comprende que el método es ya inherente a la filosofía misma. En realidad, elaborar la metodología es ya hacer filosofía, en canto que en ello se empeña necesariamente una concepción filosófica de la filosofía (cfr. Folscheid-Wunenburger, 1996: 16).

Por esto un segundo principio fundamental, que se podría llamar más 'metodológico', es el de adquirir progresivamente el arte de desarrollar las actitudes para razonar ben y juzgar respecto a la realidad de las cosas, de las personas, de los sucesos, de un problema o respecto a una serie de cuestiones ligadas entre ellas, alcanzando una suerte de autonomía y de madurez intelectual. El filósofo no puede prescindir de enfrentarse con modalidades de razonamiento, con hipótesis, premisas, consecuencias, elecciones de campo, conclusiones. Por eso no se puede prescindir, junto con el dominio de las técnicas de lectura y de la interpretación de los textos, de la disciplina lógica y teorética que implica el tratamiento sistemático de cuestiones clásicas.

De hecho, no hay mejor oportunidad para educar y ejercitar el propio pensamiento en la coherencia y rigor.

Esforzarse en pensar a fondo sobre un determinado argumento, para analizar y producir -escriben Folscheid y 
Wunenberger describiendo qué es la disertación filosófica- de los conceptos articulándolos en y mediante un discurso; no hay otro medio para ponerse en la necesidad de deber construir una problemática. En pocas palabras, la disertación, en filosofía, es insustituible, esencia: reconduce a la esencia del acto de hacer filosofía (cfr. ibíd.: 175).

Precisamente a partir de la identidad y de la índole que caracteriza la investigación filosófica en general, se podría decir que la primera aportación que la metodología filosófica puede ofrecer a las otras disciplinas científicas está justamente en la clarificación fundamental, a partir del punto de vista epistemológico, de qué es 'método'. Baste pensar no solo en cómo el Discurso sobre el método es una de las temáticas afrontadas tradicionalmente por los filósofos, sino cómo algunos conceptos filosóficos fundamentales, como el de analogía, resultan básicos para poder reconocer las peculiaridades de cada uno de los métodos que son propios de diferentes disciplinas, garantizando sin embargo en estos diferentes casos, las comunes características de la cientificidad (objetividad, rigurosidad sistemática, revisabilidad y autocrecimiento, autonomía relativa) (Prellezo-García, 1998: 26-32), siendo solo ellas las que permiten poder hablar de interdisciplinariedad, multidisciplinariedad, transdisciplinariedad, etcétera.

Nos parece interesante recurrir, a este respecto, al valor del pensamiento del cardenal John Henry Newman, así como emerge de sus escritos filosóficos (Oxford University Sermons y Grammar of Assent) y de su Idea of a University: muy interesante es su concepción de la relación entre la educación y la filosofía. En el pensamiento de Newman, la filosofía es ante todo un hábito de la mente, "una suerte de ciencia distinta a todas las demás, y en algún sentido, una ciencia de las ciencias". El resultado de su aplicación al saber es la formación de la mente o de 
una facultad crítica, capaz de dar sentido a los hechos y de reunirlos en la expresión de un todo. La filosofía es un hábito de orden y de sistema, un hábito que refiere todo acto de conocimiento a lo que ya conocemos. Esto significa un verdadero crecimiento del intelecto, no una recepción pasiva de un cierto número de nuevas ideas sin ninguna relación con el aprendizaje previo. Si la filosofía es un hábito de la mente, debe ser supremo fin de la educación de la persona; no puede ser enseñada como cualquier otra ciencia. Sus contenidos ayudan a los estudiantes a desarrollar su inclinación interior a la filosofía. De este modo pueden aprender que la razón no es solo una, sino que es plural: razón lógica y explícita, como la de las ciencias demostrativas; razón práctica e implícita, como la phrònesis de Aristóteles, y el illative sense de Newman. En la escuela o en la universidad los estudiantes pueden aprender la filosofía como un hábito de la mente a través de textos filosóficos y de su interpretación y comprensión. De hecho, el interés de Newman por la persona como totalidad es similar a la posición personalista de las hermenéuticas filosóficas contemporáneas. Debemos ver cómo los textos filosóficos pueden ser leídos por los alumnos siguiendo el círculo hermenéutico y la idea personalista de la vida humana, como Newman lo anticipó en el siglo XIX (cfr. Marchetto en Desbouts-Mantovani, 2010: 145-165).

\section{Conclusión}

La vida humana en todas sus dimensiones es un enfoque perenne de dos elementos heterogéneos: el hombre y su antagonista, ese 'otro' que no es el hombre y lo rodea, lo envuelve y aprisiona, llámesele circunstancia o mundo o Dios o como se quiera... ese tener la falta de algo que nos es menester, este ser sustancial y activamente menesteroso es la condición del hombre (Ortega y Gasset, 2008: 611). 
Esta significativa cita de J. Ortega y Gasset nos permite encaminar las conclusiones de estas nuestras reflexiones, recordando cómo toda la existencia humana, que es al mismo tiempo maravilla y paradoja, devuelve necesariamente a esas cuestiones fundamentales de las que se ocupa la metafísica. El hombre, que reconoce en sí mismo un misterio, está abierto ante el misterio de la realidad misma en el que está inmerso, y ante el misterio de la realidad que lo trasciende. La mirada metafísica sobre su condición existencial, cultivada y -en la medida de lo posible- transmitida y enseñada a las nuevas generaciones, constituye una tarea ineludible, también en contextos relativistas o nihilistas, para quien aprecia la verdad integral de la existencia humana.

Obrando así, se entiende también el gran valor epistemológico del diálogo y del recíproco enriquecimiento interpersonal e interdisciplinar.

Hoy no se puede dejar de analizar el tema de la interdisciplinariedad como aproximación integrada al conocimiento como emerge de la tendencia difundida en las ciencias de sobrepasar los confines entre las disciplinas, especialmente frente a una realidad que aparece siempre más compleja e interrelacionada. Ubicados histórica y culturalmente en el ámbito del debate que en la segunda mitad del siglo XX ha llevado a definir más claramente los contenidos y las problemáticas, los tema de la interdisciplinariedad y de la 'transdisciplinariedad' hacen necesario y oportuno un aporte filosófico explícito que permita pensar el conocimiento y la interdisciplinariedad más allá de un horizonte meramente pragmático, en vistas a una rehabilitación antropológica que, sobre el telón de fondo de la crisis de un modelo de ciencia de corte positivista, permita dar razón de la realidad del mundo y del hombre en modo integrado y, en la medida de lo posible, unitario (cfr. Falabella, 2010: 287-308). 
En este sentido, la aproximación filosófica a lo real, cuando no se abandona a peligrosas formas de reduccionismo, promueve ese ensanchamiento de los horizontes de la racionalidad que representa hoy, justamente en el reencontrar "esta amplitud de la razón", "la gran tarea de la Universidad", ${ }^{10}$ de forma que cada uno no se cierre de modo exclusivo en su propio método y no lo considere el único caracterizado por los rasgos de la cientificidad.

Por esto, la filosofía que se cultiva al interno de la Universidad está llamada en primer lugar a acoger el reto de ejercitar, desarrollar y defender una racionalidad de 'horizontes más amplios', mostrando que 'es de nuevo posible ensanchar los espacios de nuestra racionalidad [...], conjugar entre sí la teología, la filosofía y las ciencias, respetando plenamente [...] su recíproca autonomía, pero siendo también conscientes de su unidad intrínseca. ${ }^{11}$

Una tarea, esta, para vivir en todos sus pliegues existenciales y educativos.

\section{Notas}

1 Sagrada Congregación para la Educación Católica, Decreto de reforma de los estudios eclesiásticos de Filosofía (Ciudad de Vaticano, Lev, 2011), n. 2. Cfr. Juan Pablo II, Carta encíclica Fides et ratio (Ciudad del Vaticano, Lev, 1998), n. 3.

2 Sagrada Congregación para la Educación Católica, Decreto de reforma de los estudios eclesiásticos de Filosofía, cit., n. 4. Cfr. también Juan Pablo II, Carta encíclica Fides et ratio, cit., n. 81; B. Bordignon, Dialogo tra fede e cultura nell'insegnamento (Rubbettino, Soveria Mannelli, 2011).

3 Sagrada Congregación para la Educación Católica, Decreto de reforma de los estudios eclesiásticos de Filosofía, cit., n. 1 .

4 Sagrada Congregación para la Educación Católica, Decreto de reforma de los estudios eclesiásticos de Filosofía, cit., n. 3. Cfr. Juan Pablo II, Carta Encíclica Fides et ratio, cit., n. 83 y 6. 
5 Sagrada Congregación para la Educación Católica, Decreto de reforma de los estudios eclesiásticos de Filosofía, cit., n. 4. Cfr. Juan Pablo II, Carta encíclica Fides et ratio, cit., n. 81 y 83; Tomás de Aquino, Comentario a la Metafísica de Aristóteles, Proemio; Benedicto XVI, Carta Encíclica Deus caritas est (Ciudad del Vaticano, Lev, 2006), n. 9.

6 Sagrada Congregación para la Educación Católica, Decreto de reforma de los estudios eclesiásticos de Filosofía, cit., n. 7.

7 Ibíd., n. 6. Cfr. Benedicto XVI, Carta Encíclica Caritas in veritate (Ciudad del Vaticano, Lev, 2009), n. 1, 3 y 5.

8 Sagrada Congregación para la Educación Católica, Decreto de reforma de los estudios eclesiásticos de Filosofía, cit., n. 11.

9 Ibíd., Parte II (Normas de la Constitución Apostólica Sapientia christiana), art. 60 .

10 Cfr. Benedicto XVI, Encuentro con los representantes de la ciencia en el Aula Magna de la Universidad de Regensburg (12 de septiembre de 2006).

11 Sagrada Congregación para la Educación Católica, Decreto de reforma de los estudios eclesiásticos de Filosofía, cit., n. 7. Cfr. Benedicto XVI, Discurso a los participantes de la IV Convención Eclesial Nacional, Verona, 19 de octubre de 2006, L'Osservatore Romano (20 de octubre de 2006).

\section{Bibliografía}

Aristóteles

1996 Metafísica, Madrid: Akal.

Bay M. y M. Toso (ed.)

2009 Questioni di metodologia della ricerca nelle scienze umane. Paradigmi, esperienze, prospettive, Roma: Las.

Benedicto XVI

2006 Carta Encíclica Deus caritas est. Ciudad del Vaticano: Lev.

2006 "Discurso a los participantes de la IV Convención Eclesial Nacional”, Verona, 19 de octubre de 2006, en: L'Osservatore Romano (20 de octubre de 2006).

2006 "Encuentro con los representantes de la ciencia en el Aula Magna de la Universidad de Regensburg" (12 de septiembre de 2006), en: Acta Apostolicae Sedis 98 (2006).

Bermejo, D.

2010 "Prólogo", en: Id. Homo sum. El ser humano en la filosofía española contemporánea. Logroño: Perla Ediciones. 
Bernardi W. y D. Massaro

2005 "Introduzione", en: Id. (ed.), La cura degli altri. La filosofia come terapia dell'anima, Arezzo: Università degli Studi di Siena-Facoltà di Lettere e Filosofia di Arezzo.

Bordignon, Bruno

2011 Dialogo tra fede e cultura nell'insegnamento. Soveria Mannelli: Rubbettino.

Cristoforetti, C.

2010 “Didattica della filosofia all'università dell'età libera”, en: Desbouts y Mantovani (ed.), Didattica delle scienze. Temi, esperien$z e$, prospettive. Città del Vaticano: Lev.

1971 De Unamuno M. Del sentimiento trágico de la vida. Madrid: Espasa-Calpe.

Desbouts, C. y Mauro Mantovani (ed.)

2010 Didattica delle scienze. Temi, esperienze, prospettive, Città del Vaticano: Lev.

Falabella, G.

2010 "Dall'interdisciplinarità alla transdisciplinarità, la possibilità di un contributo filosofico", en: Desbouts y Mantovani (ed.), Didattica delle scienze. Temi, esperienze, prospettive, Città del Vaticano: Lev.

Folscheid, D. y J. J. Wunenburger

1996 Metodologia filosofica. Brescia: La Scuola.

Frankfurt, H. G.

2006 La importancia de lo que nos preocupa. Buenos Aires: Katz.

Heidegger, $\mathrm{M}$.

2005 Ser y Tiempo. Santiago de Chile: Editorial Universitaria.

Inciarte, $\mathrm{F}$.

2004 Tiempo, sustancia, lenguaje. Ensayos de metafísica. Pamplona: Eunsa.

Jonas, $\mathrm{H}$.

2000 El principio vida. Hacia una biología filosófica. Madrid: Trotta.

Juan Pablo II

1998 Carta encíclica Fides et ratio. Ciudad del Vaticano: Lev.

Kant, Immanuel

1784 “Respuesta a la pregunta: ¿Qué es la Ilustración?”: artículo del 1784, en: Berlinische Monatschrift I.

Kierkegaard, S.

2007 Migajas filosóficas o un poco de filosofía. Madrid: Trotta. 
Mantovani, M. y M. Amerise (ed.)

2008 Fede, cultura e scienza. Discipline in dialogo. Città del Vaticano: Lev.

Mantovani, Mauro

2008 "Discipline in dialogo: un esercizio di 'razionalità allargata", en: Mantovani M., Amerise M. (ed.), Fede, cultura e scienza. Discipline in dialogo. Città del Vaticano: Lev.

Marchetto, $\mathrm{M}$.

2010 "Educare alla filosofia. Le lezione di John Henry Newman", en: Desbouts y Mantovani (ed.), Didattica delle scienze. Temi, esperienze, prospettive. Città del Vaticano: Lev.

Marin, $\mathrm{M}$.

2010 "Una proposta per l'insegnamento della storia della filosofia: la circolarità come mediazione tra diacronia e sincronia, la ricostruzione dell'ambiente culturale come fucina di mentalità critiche", en: Desbouts y Mantovani (ed.), Didattica delle scienze. Temi, esperienze, prospettive. Città del Vaticano: Lev.

Maritain, J.

1981 Distinguere per unire. I gradi del sapere. Brescia: Morcelliana. Ortega y Gasset, José

2008 “Principios de metafísica según la razón vital”, en: Id. Obras Completas VIII. Madrid: Taurus/Fundación Ortega y Gasset.

Platón

2003 “Apologia de Sócrates”, en: Id. Diálogos. Obra completa en 9 volúmenes I. Madrid: Gredos.

Popper, Karl

1981 Miseria dello storicismo. Milano: Feltrinelli.

Prellezo, J.M. y J. M. García

1998 Invito alla ricerca. Metodologia del lavoro scientifico. Roma: Las.

Rondinara, S.

2010 "Il ruolo della filosofia nel dialogo tra scienze della natura e teologia", en: Desbouts y Mantovani (ed.), Didattica delle scienze. Temi, esperienze, prospettive. Città del Vaticano: Lev.

Sagrada Congregación para la Educación Católica

2011 Decreto de reforma de los estudios eclesiásticos de Filosofía. Ciudad de Vaticano: Lev.

Thomas Aquinas

1866 "Sententia super Metaphysicam", en: Id. Opera Omnia, n. 20. Parmae: P. Fiaccadori. 
1852-1853 “Summa Theologiae”, en: Id. Opera Omnia, nn. 1-3, Parmae: P. Fiaccadori.

Tonelli, R.

2010 "Educar en la pregunta sobre el sentido de la vida", en: Pensar y Educar. Anuario del Instituto Superior de Filosofía "San Juan Bosco". Burgos 3.

Vásquez Ramos, D.

2011 "La virtud de la studiositas y el conocimiento. Un estudio desde Santo Tomás de Aquino", en: Cuadernos doctorales de la Facultad Eclesiástica de Filosofía de la Universidad de $\mathrm{Na}$ varra 21: 93-196.

Zambrano, M.

1992 El hombre y lo divino. Madrid: Siruela.

Zuanazzi, G.

1996 Prefazione, en: Folscheid y Wunenberger, Metodologia filosofica. Brescia: La Scuola.

Zubiri, X.

1970 Cinco lecciones de filosofía. Madrid: Moneda y Crédito. 